\title{
CAMKK2 regulates mitochondrial metabolism through succinate dehydrogenase
}

Mohammad Golam Sabbir

Carla G. Taylor

Peter Zahradka

Video Byte

Keywords: CAMKK2, succinate dehydrogenase, oxidative phosphorylation, respiratory supercomplex, respiration, Cell Communication and Signaling

Posted Date: October 13th, 2021

DOI: https://doi.org/10.21203/rs.3.rs-966304/v1

License: (c) (i) This work is licensed under a Creative Commons Attribution 4.0 International License.

Read Full License 


\section{Abstract}

Metabolic regulation is vital to maintaining energy balance throughout the body, and different cell types have different ways of maintaining this balance. CAMKK2 is an enzyme common to various cells that aids in breaking down glucose through cellular respiration, but the details of how CAMKK2 carries out that role in different cells remains unclear. To find out, researchers deleted the gene for CAMKK2 from human kidney and liver-derived cells. Deleting CAMKK2 significantly reduced cellular respiration in both cell types versus parental cells. However, isolated mitochondrial respiration increased in kidney cells but decreased in liver cells. Proteomic analysis traced this difference to translational and transcriptional changes in succinate dehydrogenase (SDH). SDH is the only enzyme complex that participates in both the Krebs cycle and electron transport chain. Removing or overexpressing SDH subunit B in CAMKK2deleted cells confirmed the functional link between SDH and CAMKK2. Understanding this functional relationship could help researchers develop new drugs for the treatment of metabolic diseases. 